\title{
Managerial Optimism and Investment Choice
}

\author{
Florian Englmaier* \\ Department of Economics, University of Munich, Munich, Germany
}

\begin{abstract}
This paper analyzes whether it might be desirable for a firm to hire an overoptimistic manager to commit to a certain $R \& D$ strategy. I consider a Cournot model with an ex-ante $R \& D$ stage where firms can invest in cost reduction before product market competition takes place. I show that firms want to hire overoptimistic managers and argue that a manager's type may serve as a substitute for strategic delegation via contracts. Copyright (C) 2010 John Wiley \& Sons, Ltd.
\end{abstract}

The use of thugs and sadists for the collection of extortion or the guarding of prisoners, or the conspicuous delegation of authority to a military commander of known motivation, exemplifies a common means of making credible a response pattern that the original source of the decision might have been thought to shrink from or to find profitless, once the threat had failed.

Thomas Schelling (1960, p. 142/3)

\section{INTRODUCTION}

A firm's choice of a top executive is often considered as commitment to or a signal of change of existing corporate policies. When Bayer hired Marijn Dekkers to take over the pharma company in 2010 , this was considered a commitment to Bayer's realignment strategy. ${ }^{1}$ Similarly, Henkel's choice of Kasper Rorsted in 2008 was viewed as a commitment to the course of internationalization that had been started by his predecessor Ulrich Lehner, as Rorsted had shown his strength in this field and at managing difficult

\footnotetext{
*Correspondence to: Department of Economics, University of Munich, Ludwigstr. 28 III VG, 80539 Munich, Germany. E-mail: englmaier@Imu.de
}

changes at his former employer Hewlett-Packard. ${ }^{2}$ Bertrand and Schoar (2003) have shown that individual managers affect corporate behavior and performance. They find that the manager as a person matters for a wide range of corporate decisions. A significant extent of the heterogeneity in investment, financial, and organizational practices of firms can be explained by the presence of manager-fixed effects. Summing up, the perso$\mathrm{n}$ (ality) of a top-executive has in itself substantial influence on a firm's policy.

Recently, economists have increasingly incorporated findings from psychology. One of the best-established features of human behavior is the presence of overoptimism or self-serving biases. Miller and Ross (1975), Langer and Roth (1975), and Nisbett and Ross (1980) document the presence of a self-serving bias as people tend to account their success mainly on their own ability while it is in fact mainly due to luck. Bettman and Weitz (1983) find evidence for this behavior among executives in their analysis of annual reports. Overoptimism, where people believe favorable events to be more likely than they actually are, is documented by Alpert and Raiffa (1982), Buehler et al. (1994), Weinstein (1980), and Kunda (1987). Already early on, the possible importance of these findings for businesses was understood and studied. Kidd and Morgan (1969) found that 
electric utility managers consistently underestimated the downtime of generating equipment. Larwood and Whittaker (1977) studied a sample of corporate presidents and found them to be unrealistic in their predictions of success. Cooper et al. (1988) look at entrepreneurs who overestimate their chances of success with their business. In their sample of 2994 entrepreneurs, $81 \%$ believe their chances to survive are better than $70 \%$ and $33 \%$ believe they will survive for sure. In reality, $75 \%$ of new ventures did not survive the first 5 years.

In economics, Malmendier and Tate (2005) find that overoptimistic managers take value-destroying actions as they overestimate the returns to their investment projects and view external funds as unduly costly. Thus, they overinvest when they have abundant internal funds, but curtail investment when they require external financing. Malmendier and Tate (2008) argue that overoptimism helps to explain merger decisions. Overoptimistic CEOs overestimate their ability to generate returns. As a result, they overpay for target companies and undertake value-destroying mergers. Again, the effects are strongest if they have access to internal financing.

But why do firms hire managers who appear to destroy value, as they are too optimistic about the true business environment? This is even more surprising as Malmendier and Tate's results indicate that overoptimism is an (at least somewhat) observable characteristic. This paper suggests a rational interpretation: It might pay for a firm to hire an overoptimistic manager for strategic reasons. By hiring such an 'irrational' type, the firm can commit to act differently in product market competition and it might try to use this to get a competitive edge over its competitors. This follows the intuition summarized in the quote by Thomas Schelling at the beginning of the paper that by delegating certain tasks to agents with preferences different from one's own, one can make threats credible that were not individually rational to carry out if oneself would act. ${ }^{3}$

I analyze a duopoly model of Cournot competition in which the firms have the opportunity to carry out cost reducing R\&D before they enter into product market competition. Following Brander and Spencer (1983), who were the first to analyze the strategic effects of $R \& D$ on later competition, I find that both firms will hire overoptimistic managers. Dependent on the demand structure, the option to delegate can improve or worsen the profit situation for the firms. A key assumption in my analysis is that a manager's type is publicly observable which I consider a reasonable approximation for imperfectly competitive industries with only a limited number of players. There, as hinted in the examples given in the beginning of the paper, a lot of information is available about the relevant individuals.

\subsection{Related Literature}

There have been several attempts to highlight the upsides of overoptimistic managers but those focussed on intra-firm issues. ${ }^{4}$ Rotemberg and Saloner (2000) show that incentives for innovation can be enhanced by employing a 'visionary' CEO whose vision biases him in favor of certain projects. CEO vision changes which projects get implemented and thus affects the incentives of employees who can be compensated for their innovative ideas only when they become embodied in implemented projects. Hence, vision stipulates initiative. Similarly, Van den Steen (2005) shows that a manager with strong beliefs about the right course of action will attract, through sorting in the labor market, employees with similar beliefs. This alignment of beliefs gives direction to the firm and improves incentives and eases coordination. Bolton et al. (2008) show that 'leader resoluteness', or vision, is valuable in a setting where the best course of action for the organization is learned only over time. Leader resoluteness slows down the leader's learning and thus improves the credibility of the mission statement and, again, improves incentives and eases coordination.

The classic literature on strategic delegation analyzes how contract design can create commitment for managers. In models of Cournot competition, Vickers (1985) shows that optimal contracts have elements of relative performance evaluation, inducing the agent to act more aggressively and Fershtman (1985) provides an example that firm profits increase if managerial incentive contracts condition not only on profits but also entail a positive premium on sales.

Zhang and Zhang (1997) and Kopel and Riegler (2006), correcting a mistake in Zhang and Zhang's analysis, analyze a Cournot model with the possibility to ex ante perform R\&D with spillovers. They derive the structure of contracts conditioning on profits and sales and show that 
delegating the production and R\&D decisions to managers can be profitable for the owners of the firm. Kräkel (2004) considers oligopolistic contests with R\&D spillovers and strategic delegation. He derives the structure of (profits and sales) contracts and shows that, dependent on the strength of R\&D spillovers, a managerial firm may have a strong strategic advantage when competing with an owner operated firm. Overvest and Veldman (2008) study how an observable and verifiable contract that provides direct monetary incentives for cost reductions can overcome the problem that cost-reducing investments may not be publicly observable and thus cannot be used as strategic commitments.

My model is complementary to the above studies. In situations where for some reasons, e.g. contractibility problems or regulatory restrictions, it is not possible to use distorted contracts, selecting an overoptimistic manager may be a valuable alternative strategy. In my model, the overoptimistic manager expects the product market to be more profitable than it actually is and hence overoptimism helps to commit to an aggressive $R \& D$ strategy.

The remainder of this paper is structured as follows. Section 2 analyzes a model of Cournot competition. Section 3 discusses possible extensions and concludes. The Appendix contains derivations.

\section{COMPETITION IN QUANTITIES}

\subsection{Model}

We consider a model where two firms compete in quantities. They face a linear inverse demand $p=a-b \sum q_{i}$, with $i \in\{1 ; 2\}$. Before they enter the product market competition stage, firms can invest in cost-reducing R\&D. By doing so, they can reduce their initially identical marginal costs of production $C$ by $\theta_{i}$ with $\theta_{i} \in[0, C] .{ }^{5}$ Thus, firm $i$ 's final marginal costs of production are $c_{i}\left(\theta_{i}\right)=$ $C-\theta_{i}$. To ease exposition, we assume that $a-C>0$, i.e. the market is initially profitable. However, the firm has to bear a convex cost $\gamma_{i}\left(\theta_{i}\right)=\frac{1}{2}\left(\theta_{i}\right)^{2}$ for cost-reducing investments.

In an initial stage, the firm has to hire a manager to carry out R\&D and production. I abstract from agency conflicts within the firm, i.e. the manager acts as if he were residual claimant to the firm's profits. The manager can be overoptimistic, which is modeled as follows. As pointed out in Section 1, overoptimistic agents, maybe due to illusion of control, underestimate (overestimate) the probability of bad (good) events. It is assumed that in the initial stage, when the R\&D investments have to be taken, the market demand is not yet known. One may think of a lottery over different levels of $a$ in the inverse demand, keeping $b$ fixed. An overoptimistic manager underestimates the risk of low realizations of $a$ and therefore expects a higher expected market size. Owing to risk neutrality, I suppress the probabilistic notation and focus on expected values to ease exposition. A manager's expectation $A_{i}$, with $A_{i}>0$, of $a$ determines his type. The managers who are hired correctly perceive their opponents' beliefs about the market but do not adjust theirs accordingly. Thus this is also a model of differing priors as in Van den Steen (2005) where agents observe differing beliefs but stick with their own. However, once the true $a$ has been realized the agents maximize profits, given the previous $R \& D$ investments. The timing of the model is as follows: $t=0$-Firms simultaneously hire a (possibly overoptimistic) manager.

$t=1$-The managers simultaneously decide about the R\&D investment, given their (optimistic) expectations.

$t=2-$ The true market size is revealed.

$t=3$ Firms compete in quantities.

Note that this three-stage game is not globally well behaved. Inspecting the second-order condition of the problem shows that for low values of $b$, namely $b \leqslant \hat{b} \approx 1.56 \ldots$, the secondorder conditions are not necessarily negative and hence the first-order conditions are not sufficient to characterize the solution. Hence, for smaller values of $b$ corner solutions are optimal, see Appendix A.2 for a discussion. For the remainder of the analysis, I focus on the case $b \geqslant \hat{b}$ where the solution is interior.

\subsection{Analysis}

The subgame-perfect Nash equilibrium of the game is derived by backwards induction. In the product market competition stage, the managers simultaneously maximize firm profits by setting quantities. To save on space, I present the problem and solutions only from firm i's perspective. The 
expression for firm $j$ is completely analogous. Firm $i$ 's problem is given by

$$
\max _{q_{i}} \Pi_{i}=\left(\left(a-b\left(q_{i}+q_{j}\right)\right)-c_{i}\left(\theta_{i}\right)\right) q_{i}-\frac{1}{2}\left(\theta_{i}\right)^{2} .
$$

From the resulting first-order conditions, we can derive the standard reaction functions, the equilibrium quantities, ${ }^{6}$ and equilibrium profits

$$
\Pi_{i}^{*}=\frac{\left(a-C+2 \theta_{i}-\theta_{j}\right)^{2}}{9 b}-\frac{1}{2}\left(\theta_{i}\right)^{2} .
$$

These profits are used in the $R \& D$ investment stage where managers maximize expected profits, given their belief of the market size $A_{i}$ by simultaneously choosing $\theta_{i}$ and $\theta_{j}$. The problem for $i$ is hence

$$
\max _{\theta_{i}} \Pi_{i}^{*}=\frac{\left(A_{i}-C+2 \theta_{i}-\theta_{j}\right)^{2}}{9 b}-\frac{1}{2}\left(\theta_{i}\right)^{2} .
$$

From the first-order conditions the reaction functions ${ }^{7}$ are derived, which are relevant for the optimal action of the firm in the stage where firms can decide whether to hire an overoptimistic manager with a belief $A_{i} \neq a$ For such agents the reaction functions become

$$
\theta_{i}\left(\theta_{j}\right)=\frac{4 A_{i}-4 C-4 \theta_{j}}{(9 b-8)} .
$$

From these we can solve for the equilibrium values of $\theta_{i}^{*}$ as functions of the respective beliefs about the market size:

$$
\theta_{i}^{*}\left(A_{i}, A_{j}\right)=\frac{48 C-36 C b-32 A_{i}-16 A_{j}+36 b A_{i}}{81 b^{2}-144 b+48} .
$$

Note that for $A_{i}=A_{j}=a$ the equilibrium values boil down to the standard result $\theta_{i}^{*}=\theta_{j}^{*}=$ $(36 b-48)(a-C) /\left((9 b-8)^{2}-16\right)$.

The firms' problem is to maximize expected profits by simultaneously choosing a manager with type $A_{i}$. Firm i's problem takes the form

$$
\begin{aligned}
\max _{A_{i}} \Pi_{i}^{*}= & \frac{\left(a-C+2 \theta_{i}\left(A_{i}, A_{j}\right)-\theta_{j}\left(A_{i}, A_{j}\right)\right)^{2}}{9 b} \\
& -\frac{1}{2}\left(\theta_{i}\left(A_{i}, A_{j}\right)\right) .
\end{aligned}
$$

As there are closed form solutions for $\theta_{i}\left(A_{i}, A_{j}\right)$ and $\theta_{j}\left(A_{i}, A_{j}\right)$, we can use them in this problem. Plugging these solutions in and differentiating gives the reaction functions ${ }^{8}$ and allows to solve for the equilibrium values of $A_{i}^{*}$ and $A_{j}^{*}$

$A_{i}^{*}=A_{j}^{*}=\frac{\left(8 a-6 C b-30 a b+27 a b^{2}\right)}{27 b^{2}-36 b+8}$.

This equilibrium is, given the parameter restrictions, symmetric and unique. For this parameter range, it is easily verified that the firms always choose to hire overoptimistic managers

$$
A_{i}^{*}=\frac{\left(8 a-6 C b-30 a b+27 a b^{2}\right)}{27 b^{2}-36 b+8}>a .
$$

After rearranging, one can see that this holds whenever, as it is assumed, $(a-C)>0$. Proposition 1 summarizes this result.

Proposition 1: The unique and symmetric equilibrium, given the parameter restrictions, has both firms delegating to overoptimistic managers.

The degree of equilibrium overoptimism is always positive, but strictly decreasing in $b$ for the relevant parameter range, $\partial A_{i}^{*} / \partial b<0$. Given the equilibrium results for $A_{i}^{*}$ and $A_{j}^{*}$ the equilibrium $\mathrm{R} \& \mathrm{D}$ levels under delegation to overoptimistic managers

$$
\theta_{\text {OO }}^{*}=\theta_{i}^{*}=\theta_{j}^{*}=\frac{(12 b-8)(a-C)}{27 b^{2}-36 b+8}
$$

and the equilibrium profits

$$
\begin{aligned}
\Pi_{O O}^{*} & =\Pi_{i}^{*}=\Pi_{j}^{*} \\
& =\frac{\left(32+160 b-216 b^{2}+81 b^{3}\right)(C-a)^{2}}{1728 b^{2}-576 b-1944 b^{3}+729 b^{4}+64}
\end{aligned}
$$

chosen by the overoptimistic managers can be derived.

\subsection{Profit Comparison}

Though it is the unique equilibrium of this game that both firms symmetrically delegate to overoptimistic managers, it is interesting to see whether the possibility to delegate is actually beneficial for the firms or whether they are in a prisoner's dilemma type of situation. Remember that the profits with delegation $\left(\Pi_{O O}\right)$ are given by

$$
\Pi_{O O}^{*}=\frac{\left(32+160 b-216 b^{2}+81 b^{3}\right)(C-a)^{2}}{1728 b^{2}-576 b-1944 b^{3}+729 b^{4}+64}
$$

and without delegation $\left(\Pi_{n O o}\right)$ by

$$
\Pi_{\text {nOO }}^{*}=\frac{(9 b-8)(C-a)^{2}}{(9 b-4)^{2}} .
$$

Comparing these two expressions we find that

$$
\begin{aligned}
\Pi_{O O}^{*}>\Pi_{\text {nOO }}^{*} \Leftrightarrow & 6624 b^{2}-4928 b \\
& -1296 b^{3}+1024>0
\end{aligned}
$$

which holds whenever $b<4.2625 \ldots$, i.e. for moderate values of $b$ firms do better by delegating to managers who are possibly overoptimistic while 


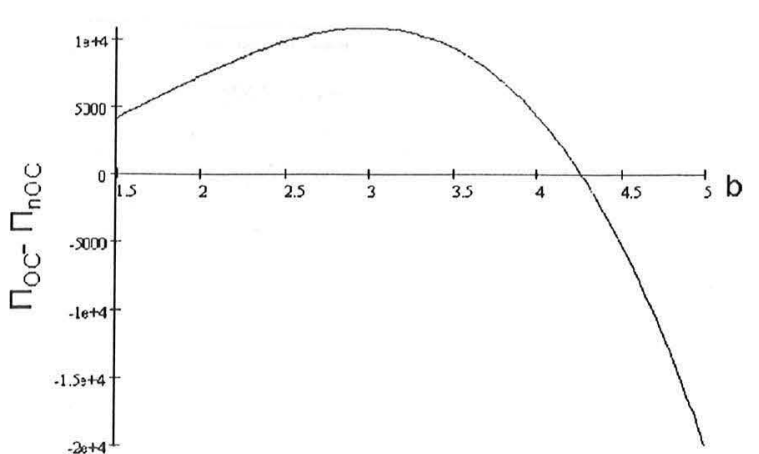

Figure 1. Difference in profits.

later on they loose out. Figure 1 shows a graph of the profit difference. Proposition 2 summarizes this result.

Proposition 2: For moderate values of $b$, firms can gain from the possibility to delegate. For high values of $b$ they face a prisoner's dilemma.

\subsection{R\&D Level Comparison}

One can also take a more welfare-oriented point of view and compare the R\&D activities under the different regimes. Recall from the above analysis that the equilibrium R\&D levels for the duopoly case without delegation $\theta_{\text {noo }}^{*}=$ $(48-36 b)(C-a) /\left((9 b-8)^{2}-16\right)$ and for the duopoly with delegation to an overoptimistic manager $\theta_{O O}^{*}=(8-12 b)(C-a) / 27 b^{2}-36 b+8$. We can compare these to the monopoly case ${ }^{9}$ $\theta_{M}^{*}=(a-c) /(2 b-1)$ and to the social planner's $\mathrm{R} \& \mathrm{D}$ decision $\theta_{S P}^{*}=(a-c) /(b-1) .{ }^{10}$

Comparing the duopoly with delegation to the duopoly without delegation we find that

$$
\begin{aligned}
\theta_{\text {OO }}^{*} & =\frac{(8-12 b)(C-a)}{\left(27 b^{2}-36 b+8\right)}>\frac{(48-36 b)(C-a)}{((9 b-8)-16)} \\
& =\theta_{\text {nOO }}^{*}
\end{aligned}
$$

holds for all $b>\hat{b}$, i.e. in the parameter region under consideration, there is always more R\&D investment in the case of delegation.

Comparing the duopoly without delegation to the monopoly case we find that

$$
\theta_{n O O}^{*}=\frac{(48-36 b)(C-a)}{\left((9 b-8)^{2}-16\right)}<\frac{(a-C)}{(2 b-1)}=\theta_{M}^{*}
$$

holds for all $b>\hat{b}$, i.e. in the parameter region under consideration, there is always more R\&D investment in monopoly. If we, however, compare the duopoly with delegation to the monopoly case we find that

$$
\theta_{O O}^{*}=\frac{(8-12 b)(C-a)}{\left(27 b^{2}-36 b+8\right)}>\frac{(a-C)}{(2 b-1)}=\theta_{M}^{*}
$$

holds for some interval of $b$, i.e. if $b \in\left[\hat{b}, \frac{8}{3}\right]$. However, even under delegation the social planner's R\&D investment is never reached as

$$
\theta_{O O}^{*}=\frac{(8-12 b)(C-a)}{\left(27 b^{2}-36 b+8\right)}<\frac{(a-c)}{(b-1)}=\theta_{S P}^{*}
$$

always holds.

Though delegation can never lead to the firstbest investment in R\&D, it can, for some parameter region, improve upon the monopoly investment level. Proposition 3 summarizes the findings.

Proposition 3: Delegation to overoptimistic managers is desirable from a welfare point of view as it increases the R\&D spending as compared to non-delegation. For some intermediate values of $b$, the investment level can even be higher than in the monopoly case.

\section{DISCUSSION AND CONCLUSION}

The analysis has shown that in quantity competition with cost-reducing R\&D investments bilateral delegation to overoptimistic managers is the unique equilibrium. Dependent on the demand structure, firms benefit or suffer from the possibility to delegate.

The model in this paper delivers empirical predictions. First I find that overoptimistic managers are more likely to be found in industries where strategic interaction plays a role, i.e. they should be less widespread in strongly differentiated or monopolized industries. Second, their prevalence should more subtly depend on the demand structure. In industries where demand reacts more to price changes, there should be less overoptimistic managers.

It would also be interesting to see whether the result by Miller and Pazgal (2001) holds in a common framework in the presence of overoptimism as well. They show the equivalence of price and quantity competition under strategic delegation with optimal contracts. Their intuition is that delegation makes competition more aggressive under Cournot and less aggressive under Bertrand competition. If the contract set is rich 
enough, the solutions to the two problems will coincide.

\section{APPENDIX A}

\section{A.1. Reaction Functions for the Cournot Competition Case}

Reaction functions at the quantity choice stage:

$$
q_{i}\left(q_{j}\right)=\frac{a-C+\theta_{i}-b q_{j}}{2 b} .
$$

Equilibrium quantities:

$$
q_{i}^{*}=\frac{a-C+2 \theta_{i}-\theta_{j}}{3 b} .
$$

Reaction functions at the cost-reduction stage:

$$
\theta_{i}\left(\theta_{j}\right)=\frac{4 \tilde{a}-4 C-4 \theta_{j}}{(9 b-8)} .
$$

Reaction functions at the hiring stage:
Inspecting Figure A1 shows that the condition is not globally well behaved. For $b \leqslant 1.56 \ldots$ we get corner solutions either at $A_{i}=a$ or at $A_{i}=\bar{A}$ where $\bar{A}$ is implicitly defined by $\theta_{i}^{*}\left(A_{i}\right)=C$. Comparing the profits for $a$ and $\bar{A}$ shows that the nature of the corner solution depends on the difference $(a-C)$. For small differences $A_{i}=a$ is more likely and for larger differences $A_{i}=\vec{A}$ is more likely as thesymmetric equilibrium. Inspecting Figure A2 in contrast ensures that for $b>1.56 \ldots$ the second-order condition is strictly negative, hence the problem is well behaved and we can focus on interior solutions.

\section{A.3. Derivation of $\theta_{M}$ for the Monopoly Case}

The monopolist solves first for the solution to

$$
\begin{gathered}
A_{i}\left(A_{j}\right)=\frac{\left(24 C b-32 a+144 a b-8 b A_{j}-18 C b^{2}\right.}{160 b-216 b^{2}+81 b^{3}-32} \\
\text { A.2. Second-order Condition for the Cournot } \\
\text { Competition Case }
\end{gathered}
$$

The second-order condition is given by

$$
\frac{\partial^{2}\left(\Pi_{i}\right)}{\partial A_{i} \partial A_{i}}=\frac{3456 b^{2}-2560 b-1296 b^{3}+512}{2304 b-13824 b^{2}+28512 b^{3}-23328 b^{4}+6561 b^{5}}
$$

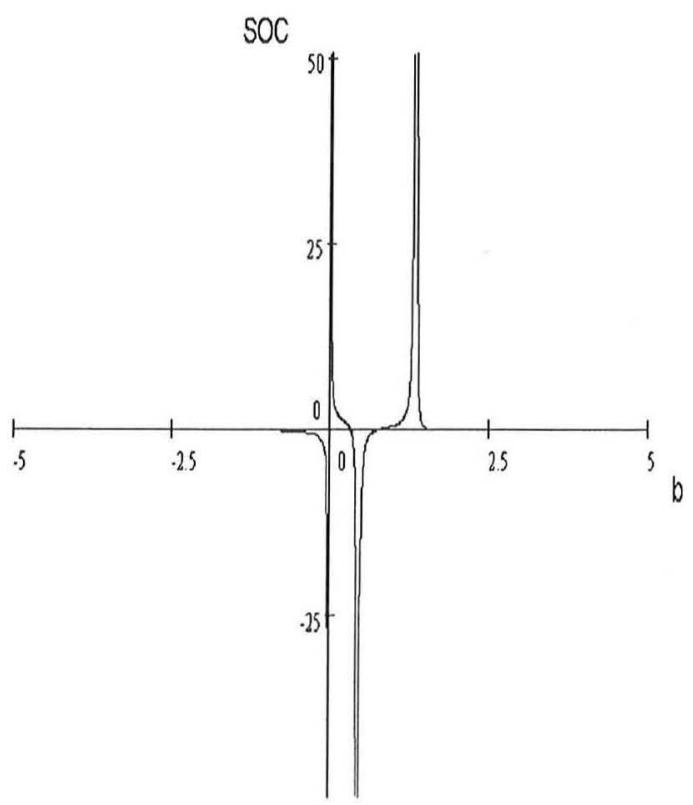

Figure A1. Second-order condition-global.
Differentiating and rearranging gives the optimal R\&D investment $\theta_{M}^{*}=(a C) /(2 b 1)$ and the monopolist's profit $\Pi_{M}^{*}=(a-C)^{2} /(2 b-1)$ can be derived.

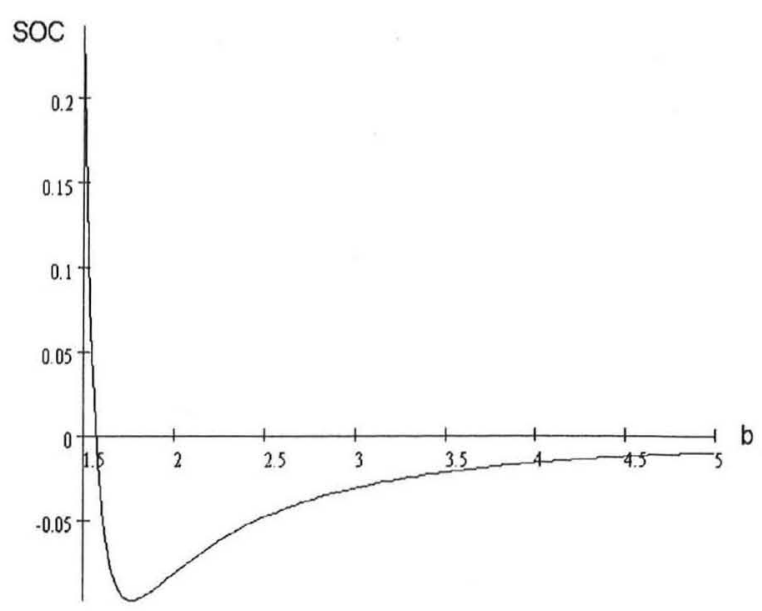

Figure A2. Second-order condition-details. 
Would a monopolist ever want to delegate to an overoptimistic manager? To check this, plug in equilibrium the values for $\theta_{M}, \theta_{i}^{*}=\left(A_{M}-C\right) /$ ( $2 b 1)$, with $A_{M} \geqslant a$ into the monopolists problem:

$$
\max _{A} \Pi_{i}=\frac{\left(a-C+\frac{C-A_{M}}{1-2 b}\right)^{2}}{4 b}-\frac{1}{2}\left(\frac{C-A_{M}}{1-2 b}\right)^{2} .
$$

Solving for $A_{M}^{*}$ gives $A_{M}^{*}=a$, hence a monopolist never delegates. Absent the strategic rationale for doing so comes at no surprise.

\section{A.4. Derivation of $\theta_{S P}$ for the Social Planner}

The social planners would offer $q_{S P}^{*}=\left(a+\theta_{S P}-c\right) / b$. Thus his initial problem

$$
\max _{\theta_{S P}} \Pi_{S P}=\frac{1}{2} q_{S P}\left(a-C+\theta_{S P}\right)-\frac{1}{2}\left(\theta_{S P}\right)^{2}
$$

becomes

$$
\max _{\theta_{S P}} \Pi_{S P}=\frac{1}{2} \frac{\left(a+\theta_{i}-c\right)}{b}\left(a+\theta_{S P}-c\right)-\frac{1}{2}\left(\theta_{S P}\right)^{2} .
$$

From the first-order condition the efficient R\&D spending $\theta_{S P}^{*}=(a C) /(b 1)$ can be derived.

\section{NOTES}

1. http://www.ftd.de/finanzen/maerkte/marktberichte/: das-kapital-bayer-holt-sich-starken-mann/50010083. html, http://www.handelsblatt.com/unternehmen/ industrie/pharmariese-bayer-leitet-neue-aera-ein; 2456922;0

2. http://www.handelsblatt.com/unternehmen/industrie/ henkel-braucht-den-frischen-wind-des-neuen-chefs; 1398916, http://www.handelsblatt.com/unternehmen/ koepfe/der-neue-saubermann;1188647;0

3. Kyle and Wang (1997) employ a similar idea with overoptimistic traders in a financial market.

4. An exception is Goel and Thakor (2008) who develop a model in which an overoptimistic manager, though he sometimes makes valuedestroying investments, has a higher likelihood than a rational manager of being promoted to $\mathrm{CEO}$. Moreover, overoptimism enhances firm value up to a point, for a risk-averse CEO.

5. The R\&D can be thought of as being stochastic with an additive error term with mean zero. As due to risk neutrality only the expected value matters, we suppress this here to ease exposition.

6. See Appendix A.1.

7. See Appendix A.1.

8. See Appendix A.1.

9. See Appendix A.3 for the derivation of this result. There I also show that a monopolist never wants to delegate decisions to an overoptimistic manager.

10. See Appendix A.4 for the derivation of this result.

\section{REFERENCES}

Alpert M, Raiffa H. 1982. A progress report on the training of probability assessors. In Judgement Under Uncertainty: Heuristics and Biases, Kahneman D, Slovic P, Tversky A (eds). Cambridge University Press: Cambridge.

Bertrand M, Schoar A. 2003. Managing with style: the effect of managers on firm policies. Quarterly Journal of Economics 118(4): 1169-1208.

Bettman J, Weitz BA. 1983. Attributions in the board room: causal reasoning in corporate annual reports. Administrative Science Quarterly 28: 165-183.

Bolton P, Brunnermeier MK, Veldkamp L. 2008. Leadership, coordination and mission-driven management. Working Paper.

Brander JA, Spencer B. 1983. Strategic commitment with R\&D: the symmetric case. Bell Journal of Economics 14(1): 225-235.

Buehler R, Griffin D, Ross M. 1994. Exploring the 'planning fallacy' why people underestimate their task completion times. Journal of Personality and Social Psychology 67(3): 366-381.

Cooper AC, Woo CY, Dunkelberg WC. 1988 Entrepreneurs' perceived chances for success. Journal of Business Venturing 3: 97-108.

Fershtman C. 1985. Managerial incentives as a strategic variable in duopolistic environment. International Journal of Industrial Organization 3: 245-253.

Goel AM, Thakor A. 2008. Overconfidence, CEO Selection, and corporate governance. The Journal of Finance 63(6): 2737-2784.

Kidd JB, Morgan JR. 1969. A predictive information system for management. Operational Research Quaterly 20: 149-170.

Kopel M, Riegler C. 2006. R\&D in a strategic delegation game revisited: a note. Managerial and Decision Economics 27(7): 605-612.

Kräkel M. 2004. R\&D spillovers and strategic delegation in oligopolistic contests. Managerial and Decision Economics 25: 147-156.

Kunda Z. 1987. Motivated inference: self-serving generation and evaluation of causal theories. Journal of Personality and Social Psychology 53: 636-647.

Kyle AS, Wang A. 1997. Speculation duopoly with agreement to disagree: can overconfidence survive the market test? The Journal of Finance 52(5): 2073-2090.

Langer E, Roth J. 1975. Heads I win, tails it's chance: the illusion of control as a function of the sequence of outcomes in a purely chance task. Journal of Personality and Social Psychology 32: 951-955.

Larwood L, Whittaker W. 1977. Managerial myopia: self-serving biases in organizational planning. Journal of Applied Psychology 62: 194-198.

Malmendier U, Tate G. 2008. Who makes acquisitions? CEO overconfidence and the market's reaction. Journal of Financial Economics 89(1): 20-43.

Malmendier U, Tate GA. 2005. CEO overconfidence and corporate investment. Journal of Finance 60(6): 2661-2700.

Miller D, Ross M. 1975. Self-serving biases in attribution of causality: fact or fiction? Psychological Bulletin 82: 213-225. 
Miller NH, Pazgal AI. 2001. The equivalence of price and quantity competition with delegation. RAND Journal of Economics 32: 284-301.

Nisbett R, Ross L. 1980. Human inference: strategies and shortcomings. In Social Judgment. Prentice-Hall: Englwood Cliffs, NJ.

Overvest BM, Veldman J. 2008. Managerial incentives for process innovation. Managerial and Decision Economics 29(7): 539-545.

Rotemberg JJ, Saloner G. 2000. Visionaries, managers, and strategic direction. RAND Journal of Economics 31(4): 693-716.
Schelling T. 1960. The Strategy of Conflict. Harvard University Press: Cambridge, MA.

Van den Steen E. 2005. Organizations beliefs and managerial vision. Journal of Law, Economics, and Organization 21(1): 256-283.

Vickers J. 1985. Delegation and the theory of the firm. Economic Journal 95: 138-147.

Weinstein ND. 1980. Unrealistic optimism about future life events. Journal of Personality and Social Psychology 39: 806-820.

Zhang J, Zhang Z. 1997. R\&D in a strategic delegation game. Managerial and Decision Economics 18: 391-398. 